\title{
Control of ion loss from Mars during solar minimum
}

\author{
Stephen H. Brecht ${ }^{1}$ and Stephen A. Ledvina ${ }^{2}$ \\ ${ }^{1}$ Bay Area Research Corp., P.O. Box 366, Orinda, CA 94563, USA \\ ${ }^{2}$ Space Sciences Laboratory, UC Berkeley, 7 Gauss Way, Berkeley, CA, USA \\ (Received February 10, 2011; Revised May 14, 2011; Accepted May 30, 2011; Online published March 8, 2012)
}

\begin{abstract}
A hybrid particle code has been used to examine the interaction of the solar wind with Mars during solar minimum. The results were surprising as they produced ion loss rates from Mars far in excess of what is estimated from MEX. The results are analyzed and found to be consistent with the competition between photochemical rates and advection of the ionosphere. The simulations showed significant erosion of the ionosphere at altitudes between $200 \mathrm{~km}$ and $250 \mathrm{~km}$ altitudes. Addition of the crustal magnetic fields reduced the erosion and reduced the ion loss rates to a level consistent with the data.
\end{abstract}

Key words: Mars, ionospheric loss, crustal magnetic fields, simulation, solar wind interactions.

\section{Introduction}

The loss of Mars' atmosphere has been a topic of considerable research and conjecture. A variety of research groups are attempting to accurately estimate the loss rate using numerical techniques. Many others are examining data coming from the latest spacecraft to Mars, Mars Express (MEX). In this paper the results of our latest and improved hybrid simulations will be presented. The focus of this paper is the change of estimated loss rates as a function of a variety of parameters as well as changes in the numerical models/resolution being applied to the simulations of Mars.

Mars is one of the unique bodies on the solar system. It is small planet with a relatively mild temperature (as compared to the outer planets or Venus and Mercury), and it has water on its surface (Di Achille and Hynek, 2010). Because it has some water now and apparently had much more water in earlier epochs, it is a prime location to hunt for life we might recognize. Mars also offers an opportunity to study and understand many aspects of planetary atmospheres. Its small size means that the bow shock of Mars does not effectively thermalize the solar wind plasma in the subsolar region. There is limited space between the shock and the ionosphere relative to the collisional mean free path and the ion gyroradii of the incoming protons. In addition there is a limited amount of time for the electromagnetic thermalization process to occur (Brecht and Ferrante, 1991). Finally, its small size means that Mars has an extensive exosphere, relatively larger than any other planet (Kim et al., 1998).

The solar wind interaction with a planet unprotected by an extensive intrinsic field has been the subject of considerable study. The research has come in two forms; missions to the planets Mars and Venus, and numerical simulations. The number of papers from the Pioneer Venus Orbiter num-

Copyright (C) The Society of Geomagnetism and Earth, Planetary and Space Sciences (SGEPSS); The Seismological Society of Japan; The Volcanological Society of Japan; The Geodetic Society of Japan; The Japanese Society for Planetary Sciences; TERRAPUB.

doi:10.5047/eps.2011.05.037 bers in the thousands. The number of papers from missions to Mars is rapidly approaching a similar magnitude if not larger. One of the features seen in the data from these missions to Mars and Venus is that the solar wind interacts directly with the atmosphere/ionosphere/exosphere of these planets. This interaction is found to result in the loss of ions from these two planets. The current understanding of the solar wind interaction with Mars has been reviewed by Mazelle et al. (2004) and Nagy et al. (2004).

Major research questions revolve around the issues of the amount of water on Mars in the past and where it may have gone. There are a variety of theories on this topic. One of the more interesting and complete papers concerning this topic is by Lammer et al. (2003). In this paper the authors discuss the various mechanisms for water loss and the issue of water being tied up in the soil. The pick up of oxygen ions via the solar wind interaction with the Martian ionosphere/exosphere is proposed to be one of the major loss mechanisms (cf., Lammer and Bauer, 1991; Lundin et al., 1991, 2006; Lammer et al., 1996). Fox (1997) produced an estimate of what it would take to achieve the 2:1 ratio of hydrogen to oxygen for water loss. In her estimate the rate needed to be roughly $1 \times 10^{26}$ oxygen atoms per second or $1.2 \times 10^{8} \mathrm{~cm}^{-2} \mathrm{~s}^{-1}$. It is worth noting that a loss rate of $10^{26}$ oxygen ions per second would remove a meter of water from the entire surface of Mars in $1.72 \mathrm{~Gy}$. Data from Phobos-2, which orbited Mars during the solar maximum period, indicates a loss rate of $3 \times 10^{25}$ ions s $^{-1}$ (Lundin et al., 1989, 1990).

Over the past two decades a series of spacecraft have been sent to Mars. Phobos-2 was the first to measure loss rates for heavy ions $\left(\mathrm{O}^{+}\right.$and $\mathrm{O}_{2}{ }^{+}$being the major constituents). These measurements occurred during solar maximum and found loss rates above $10^{25}$ particles per second (Lundin et al., 1989, 1990; Verigin et al., 1991). Later the Mars Global Surveyor arrived and made a major discovery: the presence of strong crustal magnetic fields on Mars (Acuña et al., 1998). Finally, the Mars Express mis- 
sion arrived during solar minimum and began making measurements of plasma environment around Mars and found loss rates for $\mathrm{O}^{+}$ranging from $10^{23}$ particles/s (Barabash $e t$ al., 2007) to $>10^{24}$ particles/s (Lundin et al., 2008). Typically the estimates from the spacecraft found $\mathrm{O}^{+}$loss rates slightly higher than the $\mathrm{O}_{2}{ }^{+}$loss rates. Lundin et al. (2009) suggest that the cold ion loss rates do not support the 2:1 ratio of $\mathrm{H}^{+}$to $\mathrm{O}^{+}$needed to explain water loss however this argument does not include the traditional thermal loss of neutral $\mathrm{H}$ from the atmosphere. Estimates by Fox (2009) predict that the $\mathrm{O}_{2}{ }^{+}$loss rates should dominate the $\mathrm{O}^{+}$loss rates. As will be discussed later, accurate loss rate estimates from spacecraft data are difficult to make because of the complex geometry of the loss regions on Mars coupled with the fact that the removed $\mathrm{O}_{2}{ }^{+}$is not found in the same locations as the $\mathrm{O}^{+}$. While there is overlap in the respective ion loss regions, $\mathrm{O}_{2}{ }^{+}$ions are found upstream of the planet and the bow shock as well as being more structured in the "north pole" region. In this paper we define the term "north pole" as the direction of the convection electric field perpendicular to the solar wind flow and the plane containing the IMF often in the $+z$ direction in Mars-Sun coordinates.

The research to be reported in this paper will focus on the solar minimum situation. Specifically, the paper will examine the various aspects of the Martian interaction with the solar wind during the minimum period of solar activity and provide some insight into how various aspects of the interaction occurs. The main measure of merit will be the total oxygen ion loss rates. The paper will also examine the effects of improving the chemistry models and the importance of "getting the chemistry right". The simulations are part of earlier research and our participation the code comparison meetings convened in 2009 at the International Space Science Institute, ISSI, in Bern Switzerland (Brain et al., 2010; Nilsson et al., 2010). The "ISSI" meeting led to a challenge to perform a series of simulations with very detailed input conditions for comparison between the various simulation groups. For ease of comparison all of the test simulations were performed without the presence of the crustal magnetic field.

In the next section a discussion of the numerical model used and how it compares to other models will be presented. A discussion of the solar minimum results will follow. The last two sections will present a discussion of the results and then conclusions.

\section{Numerical Approach}

It has been found by researchers examining data, as well as, those performing simulations that the interaction of the solar wind with Mars leads to a very asymmetric interaction region and rapid variations in measured quantities. These characteristics mean that by the very nature of spacecraft data collection there are large spatial and temporal holes in the planetary coverage. Nevertheless, the data from spacecraft such as Phobos-2, Mars Global Surveyor, and Mars Express, (MEX), provide a wealth of information. However, the only way to fully understand the nonlinear and complex interactions suspected to occur within the ionosphere and atmosphere of Mars is via simulation coupled to comparisons to spacecraft data.
To estimate the global loss of oxygen from Mars scientists have employed two distinct numerical approaches to make these estimates. One is the MHD formalism (cf., Liu et al., 2001; Ma et al., 2002, 2004; Ma and Nagy, 2007; Harnett and Winglee, 2006) and the second is the kinetic formalism, specifically the hybrid particle code (cf., Brecht, 1990; Brecht and Ferrante, 1991; Kallio and Janhunen, 2002; Bößwetter et al., 2004; Modolo et al., 2005; Chanteur et al., 2009). In addition to these two fundamental approaches an ion tracking or Monte Carlo approach using MHD electromagnetic fields has also been tried (cf., Cravens et al., 2002; Fang et al., 2010 a, b). The ion tracking approach is an attempt to capture some of the kinetic behavior not found in the MHD code but has the disadvantage that the particle motion and fields are not self-consistent unless only the high energy plasma and not the bulk plasma is considered. A detailed discussion of the equations and assumptions contained within these approaches can be found in Ledvina et al. (2008).

The preferable numerical tool is a well resolved kinetic particle code where at least the ions are treated kinetically, such a code is a hybrid particle code. The hybrid model treats all ion species (the model can carry as many as one wishes) as kinetic particles. The ions are advanced in velocity with a simple Lorentz force equation. The electrons are treated as a massless neutralizing fluid. The electromagnetic fields are calculated self-consistently with the ion motion. Electromagnetic waves up to and including a portion of the whistler wave spectrum are carried in the code. Shock formation is included in the physics of this code and thus needs no assumptions or numerical techniques to capture the shock. The basic equations of the hybrid model are well known and need not be repeated here. See Harned (1982), Brecht and Thomas (1988), and Brecht and Ledvina (2006, 2010) for a more complete discussion. The research reported in this paper employed hybrid particle simulations using the HALFSHEL code. The HALFSHEL code has been used in simulations of unmagnetized bodies for many years (cf., Brecht, 1990, 1997a, b; Brecht and Ferrante, 1991; Brecht et al., 1993, 2000; Ledvina et al., 2004; Brecht and Ledvina, 2006, 2010).

Mars is difficult to simulate because there are three (3) parts to the simulation problem.

- The electromagnetic environment and kinetic phenomena such as: ion gyromotion and subsequent nonisotropic pressure tensors

- The ionospheric chemistry

- Collisional phenomena within the lower portion of the ionosphere with the neutral atmosphere.

One must accurately simulate electromagnetic environment (solar wind plasma, solar wind IMF, electromagnetic waves and the crustal fields of Mars) and the plasma behavior which can have gyro-rotational behavior on a scale larger than the Mars. Because the solar wind interacts directly with the atmosphere/ionosphere, one must accurately create/simulate the atmosphere/ionosphere and this requires a chemistry package that can react to the rather rapid loss of the ions into the solar wind. A constant production rate has been found to be inadequate. Worse there is a nominal 
Table 1. Chemical reactions for simulations.

\begin{tabular}{ll}
\hline Key reaction & Rate coefficient (solar minimum) \\
\hline $\mathrm{CO}_{2}+h \nu \rightarrow \mathrm{CO}_{2}^{+}+\mathrm{e}$ & $2.47 \times 10^{-7} \mathrm{~s}^{-1}$ \\
$\mathrm{CO}_{2}+h v \rightarrow \mathrm{O}^{+}+\mathrm{CO}+\mathrm{e}$ & $2.2 \times 10^{-8} \mathrm{~s}^{-1}$ \\
$\mathrm{O}+h \nu \rightarrow \mathrm{O}^{+}+\mathrm{e}$ & $8.89 \times 10^{-8} \mathrm{~s}^{-1}$ \\
$\mathrm{H}_{\mathrm{sw}}++\mathrm{O} \rightarrow \mathrm{O}^{+}+\mathrm{H}_{\mathrm{sw}}$ & $\sigma=1.0 \times 10^{-15} \mathrm{~cm}^{2}$, charge exchange with the solar wind \\
$\mathrm{CO}_{2}{ }^{+}+\mathrm{O} \rightarrow \mathrm{O}_{2}^{+}+\mathrm{CO}$ & $1.64 \times 10^{-10} \mathrm{~cm}^{-3} \mathrm{~s}^{-1}$ \\
$\mathrm{CO}_{2}{ }^{+}+\mathrm{O} \rightarrow \mathrm{O}^{+}+\mathrm{CO}_{2}$ & $9.6 \times 10^{-11} \mathrm{~cm}^{-3} \mathrm{~s}^{-1}$ \\
$\mathrm{O}^{+}+\mathrm{CO}_{2} \rightarrow \mathrm{O}_{2}++\mathrm{CO}$ & $1.1 \times 10^{-9} \mathrm{~cm}^{-3} \mathrm{~s}^{-1}\left(T_{\mathrm{i}}<800 \mathrm{~K}\right)$ \\
& $1.1 \times 10^{-9}\left(800 / T_{\mathrm{i}}\right)^{0.39} \mathrm{~cm}^{-3} \mathrm{~s}^{-1}\left(T_{\mathrm{i}}>800 \mathrm{~K}\right)$ \\
$\mathrm{CO}_{2}++\mathrm{e} \rightarrow \mathrm{CO}+\mathrm{O}$ & $3.5 \times 10^{-7}\left(300 / T_{\mathrm{e}}\right)^{0.5} \mathrm{~cm}^{-3} \mathrm{~s}^{-1}$ \\
$\mathrm{e}+\mathrm{O} \rightarrow \mathrm{O}^{+}+\mathrm{e}+\mathrm{e}$ & $\mathrm{Cravens} \mathrm{et} \mathrm{al.}(1987)$ \\
$\mathrm{O}_{2}{ }^{+}+\mathrm{e} \rightarrow \mathrm{O}+\mathrm{O}$ & $1.95 \times 10^{-7}\left(300 / T_{\mathrm{e}}\right)^{0.7} \mathrm{~cm}^{-3} \mathrm{~s}^{-1}\left(T_{\mathrm{e}}<1200 \mathrm{~K}\right)$ \\
& $7.38 \times 10^{-8}\left(1200 / T_{\mathrm{e}}\right)^{0.56} \mathrm{~cm}^{-3} \mathrm{~s}^{-1}\left(T_{\mathrm{e}}>1200 \mathrm{~K}\right)$ \\
\hline
\end{tabular}

scale size to a hybrid code and it is larger than the atmospheric scales which are roughly $20 \mathrm{~km}$ in altitude. Finally one must simulate the neutral part of the interaction. This includes ion-neutral drag, the Hall and Pedersen conductivities in the ionosphere and gravity. Several of these parts are difficult to include within a particle code.

The HALFSHEL hybrid particle code has been continually upgraded and improved (Brecht and Ledvina, 2006, 2010). These upgrades included new chemistry, collision, and ionospheric conduction models. The results to be reported in this paper include yet another upgrade to accurately simulate the electromagnetic and kinetic part, the chemistry part, and the neutral part of this problem. The code has now been adapted to resolve chemistry and collisional processes on radial scale sizes of $10 \mathrm{~km}$ while still handling the much larger plasma scales. This is the first hybrid code to accurately solve the chemistry on a particle by particle basis. It allows a ionospheric response to rapid losses via the solar wind pickup and makes the multiple species aspect of the simulations straight forward. Further, it has been modified to include the crustal fields. In the next paragraphs a description of the various physics and chemistry packages within the present HALFSHEL code will be presented.

\subsection{Collisions}

There are two general aspects of the HALFSHEL simulation code that involve collisions. The first is the ion-neutral drag created when ions collide with the neutral atmosphere. In this code the neutral atmosphere is assumed to be static. Depending on the information provided, (see the ISSI paper by Brain et al., 2010), the neutral atmosphere is represented by a one dimensional radial profile for $\mathrm{O}$, and $\mathrm{CO}_{2}$ or it can have two or three dimensional behaviors. The neutral models are based on the results of the Mars Thermaspheric General Circulation Model (Bougher et al., 1988). A hot O corona based on Chaufrey et al. (2007) may also be included. For the purpose of the research discussed here, the neutral profile only has a radial behavior (1-D). This form of the neutral profiles was used by all of the researchers in the ISSI comparison.

The HALFSHEL code treats the ion drag by individually colliding the $\mathrm{H}^{+}, \mathrm{O}^{+}, \mathrm{O}_{2}^{+}$particles with $\mathrm{CO}_{2}$ and $\mathrm{O}$ using their respective collision cross-sections. Currently, heating of the particles, thermalization (randomization) of their trajectories, is not included. The interaction is simply an energy loss from the particles being tracked. The neutral profiles are untouched as mentioned earlier, thus the energy transfer to the neutrals is not included in the simulations.

The second place where collisions enter into the HALFSHEL simulations is via the ionospheric conductivities. Since the simulations now extend down to below the exobase of Mars, collisions also affect the conductivities and thus the electric fields. Hence, the simulations dating back to before 2006 have included these conductivities. The presence of the Hall and Pedersen conductivities was important in earlier simulations (Brecht and Ledvina, 2006, 2010) but will be more important when the crustal fields are included in the simulations. The generalized electric field including the Hall and Pedersen terms comes from a text by Mitchner and Kruger (1973). In the limit that the collision frequencies go to zero, this equation returns to the normal electric field equation found in a hybrid particle code (Brecht and Thomas, 1988).

\subsection{Chemistry}

To produce and maintain the ionosphere the research reported in Brecht and Ledvina $(2006,2010)$ used the same set of ionospheric chemistry equations reported by (Liu et al., 2001; Ma et al., 2002, 2004). During and after the first conference at ISSI, the set of chemistry equations were expanded to those found in Table 1. The rate coefficients are those for the solar minimum.

Given the small scale height of the atmosphere of Mars especially in the ion pickup region (roughly $250 \mathrm{~km}$ altitude), we had concerns about the accuracy of the solutions of the chemistry equations. Testing of numerical solutions to the chemistry equations indicated that a resolution of $10 \mathrm{~km}$ in the radial direction was required for convergence using the typical neutral profiles on Mars. In addition the time step for the chemical equation solutions were found to converge with a time step of $\Delta t=0.3$ seconds or less. The plasma portion of the code has a time step of approximately 20 times smaller than the chemical time step. Further, the collisional processes needed to be resolved so that the collision frequencies times the time step are less than 1.

A fully spherical simulation seemed appropriate, however, the divergence of the resolution in angle, as one moved away from the planet, caused problems in accurately tracking electromagnetic waves. Thus it was decided to use a 


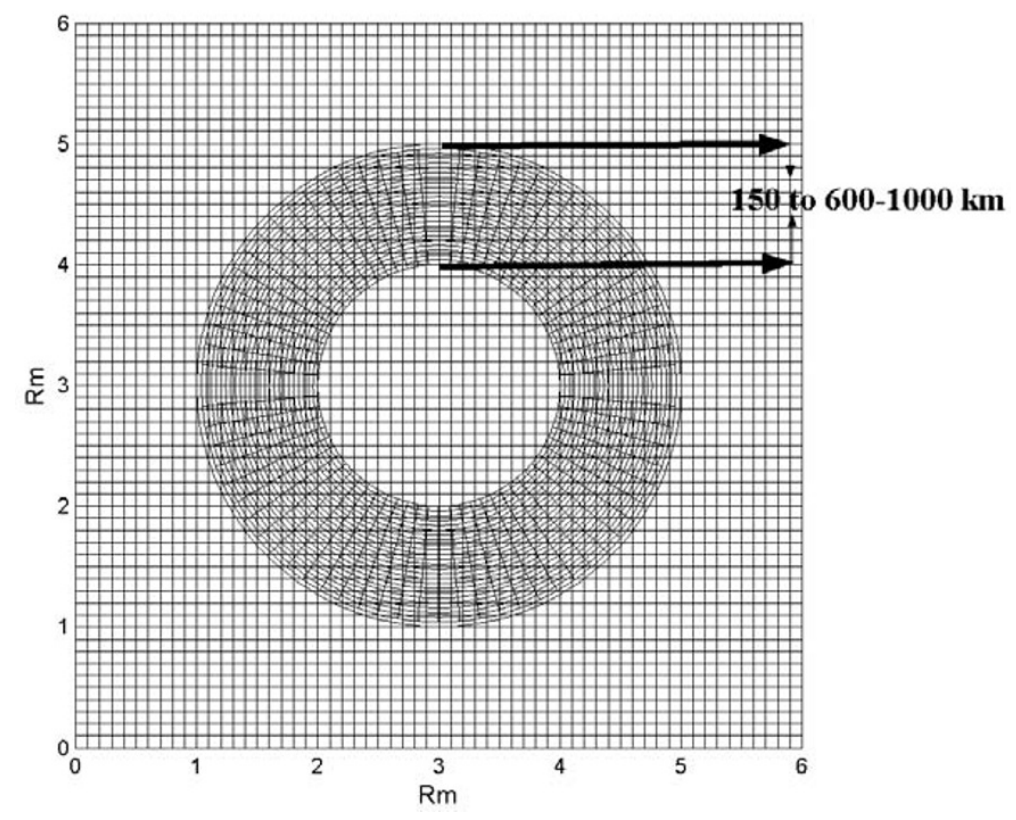

Fig. 1. This is a schematic of the Cartesian grid upon which the electromagnetic fields are solved and the "spherical" grid where the chemistry and collisions are applied to existing particles and those being created. The "spherical" grid has been expanded so that one can see some of the details. The radius of the "spherical" grid ranges between $150 \mathrm{~km}$ and $600 \mathrm{~km}$ to $1000 \mathrm{~km}$.

different tactic. The electromagnetic part of the code would be Cartesian thus the resolution did not change no matter where waves or electromagnetic structures were formed. A set of "spherical" grids were added to the simulation to resolve the neutral density profiles at much higher accuracy for a better solution of the chemistry equations shown in Table 1 and to calculate a variety of collisional plasma behaviors. The term "spherical" is used in this paper, but the grid is not a true spherical grid as it does not have the same metric as a true spherical grid: Here the metric is $r^{2} d r d \theta d \varphi$. This makes loading particles and weighting them much easier as each cell at a given radius is the same size. This approach works because there are no differential operators applied using this grid. The solution of the field equations is performed on the Cartesian grid with the particles being allocated to either grid as necessary. Figure 1 shows a schematic of the new hybrid code. The spherical grid has a typical radial resolution of $10 \mathrm{~km}$ and about $1.9^{\circ}$ angular resolution. It generally covers a range from about $150 \mathrm{~km}$ altitude to between $600 \mathrm{~km}$ and $1000 \mathrm{~km}$ in altitude. The range changes depending what neutral profile is being used and the chemical species being produced.

The chemistry is performed on the particles within the spherical grid. New particles are created if the production rate exceeds the loss rates within each spherical cell. Previously existing particles have their density decreased as recombination occurs. These spherical grids (there are several for each ionospheric species) also are used to calculate the ion-neutral drag and to apply the gravity terms as well. What makes this particularly effective is that particle locations can be easily found on either grid. Therefore, ionospheric particles that are picked up will naturally transition out of the region of chemistry and collisions into the region of pure collisionless electromagnetic interactions. Meanwhile, particles still at lower altitudes feel the electromag- netic fields from the Cartesian grid as well as the collisional forces.

The inclusion of the spherical grids into HALFSHEL was a complicated and major step in the evolution toward more accurate simulations of the solar wind interaction with Mars' ionosphere. As mentioned earlier, the chemistry code was tested externally to make sure that spatial and temporal convergence is achieved. This testing led to new insights concerning the simulations and how we were performing them. In earlier work, the ionosphere had been loaded as a profile and replenished at a specific rate in order to achieve a full ionospheric profile in a certain time. However, it was discovered that we needed to run the simulations much longer. Instead of 20,000 time steps we needed to use 50,000 or more. Although the loss rates are collected by a virtual box at $2 R_{\mathrm{m}}$ it still takes between 1,000 to 2,000 seconds for the loss rates to reach a steady state. With the crustal fields in the simulations the time to reach equilibrium often exceeds 2,000 seconds, $\sim 100,000$ time steps. If the simulations were run until the particles leaving the whole computational grid reached steady state considerably longer runs would be necessary. In the work published in 2010 Brecht and Ledvina (2010) resolved the chemistry on the Cartesian grid. Because the code was using cell sizes of $300 \mathrm{~km}$, it was found that the chemistry did not properly converge. With the new capability, the chemistry portion of the code converged properly. And at this point some surprises were found.

Figures 2 and 3 illustrate the issue. These figures show the net production rates (production-loss) for $\mathrm{O}^{+}$as a function of altitude and time with no advection present. Note, in the solar minimum case, Fig. 2, the chemistry at $200 \mathrm{~km}$ takes over 400 seconds to come into photochemical equilibrium (net flux $=0$ ). At $250 \mathrm{~km}$ altitude (generally above the exobase) it requires $\sim 5,000$ seconds while altitudes above 


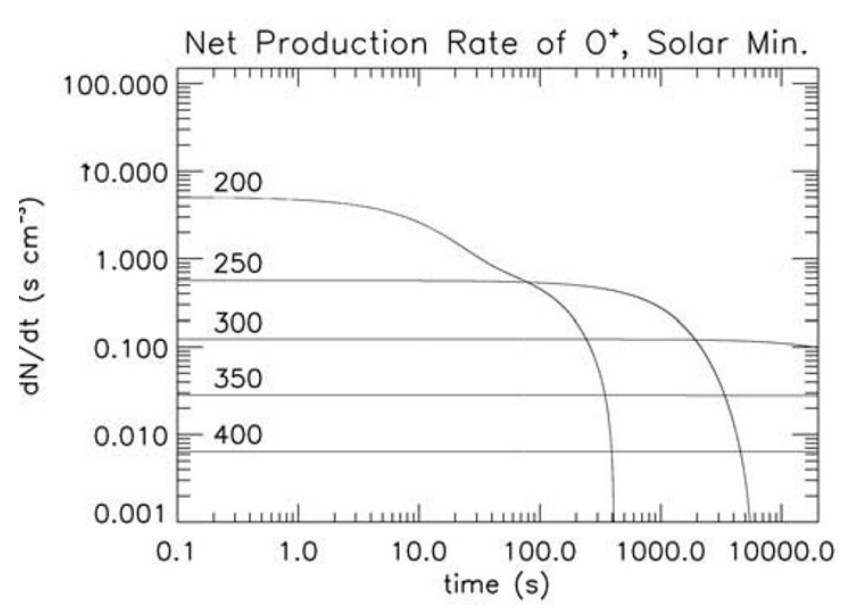

Fig. 2. The net production rates for $\mathrm{O}^{+}$at various altitudes during solar minimum conditions.

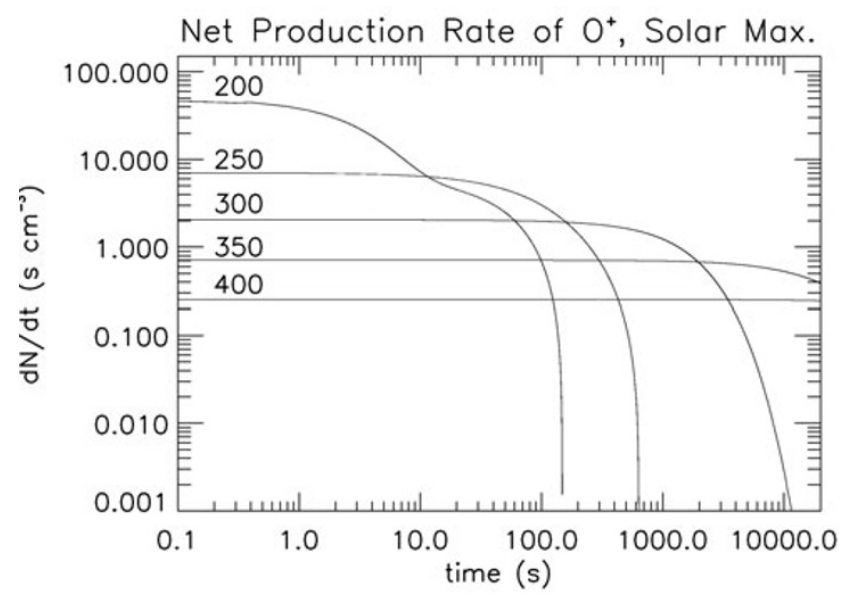

Fig. 3. The net production rates for $\mathrm{O}^{+}$at various altitudes during solar maximum conditions.

$300 \mathrm{~km}$ requires much longer ( $>50,000$ seconds) to converge. At solar maximum the time scales drop due to increased neutral density at these altitudes and the increase in solar EUV flux. This led to a quandary. How to perform the simulations? It was clear that if there was any sort of advection of the ionosphere before it was constructed the simulation would never reach appropriate ionospheric densities during the simulation. This would mean a generally lower prediction for the ion loss from Mars. The solution was to integrate the chemistry before the advection of plasma and electromagnetic fields began. The chemistry was integrated out 10,000-20,000 seconds, depending on the specific situation, until the ionosphere reached photochemical equilibrium at least up to the exobase. The results can be seen in a comparison of our chemistry to the Viking data, Fig. 4. Here one sees good agreement with the data up to a given altitude where it appears that the Martian oxygen ions are being advected to the location of the Viking landing.

In summary, the chemistry package has been tested numerically for temporal and spatial convergence. This information was then used in the HALFSHEL code to provide an accurate ionosphere. The chemistry was also tested against the Viking data and found to match well, if the chemistry

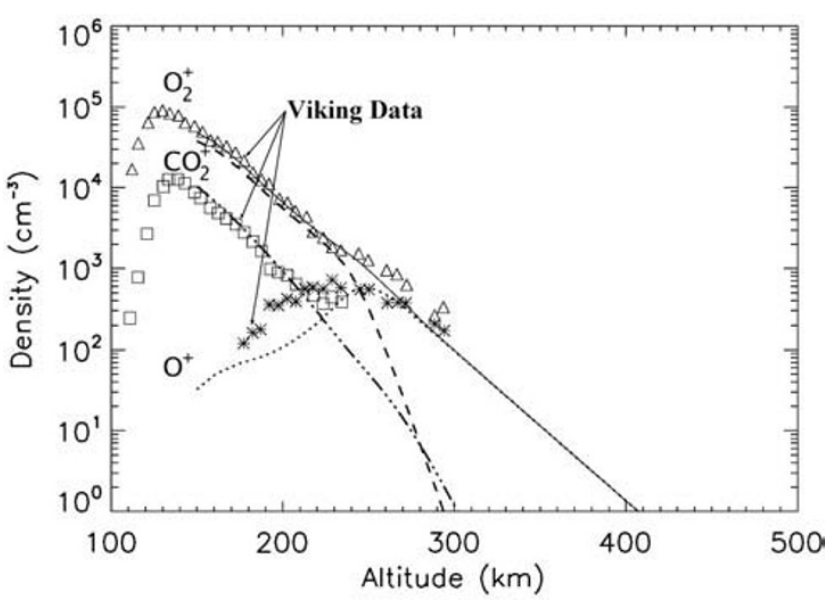

Fig. 4. Comparison of the chemistry solution with the Viking data. $\mathrm{O}^{+}$is a little low compared to the data, but may well be due to advection to the longitude and latitude of the Viking landing. The solid lines are the chemistry model results.

was properly converged. The addition of the "spherical" grids to allow higher resolution chemistry coupled with the new strategy for starting the simulation has led to some new insights into the solar wind interaction with Mars.

\section{Results}

There are many questions and uncertainties that a research program addressing Mars could address. Further, the simulations have now become very complex with enormous amounts of data being produced. To focus this paper it is worth addressing some of the data and our past discoveries from previous Mars simulations.

Our previous simulations of Mars with the hybrid code (Brecht and Ledvina, 2006, 2010) led to a variety of findings. The first was that the loss of particles did not mimic MHD code results (cf., Ma et al., 2002, 2004; Ma and Nagy, 2007). The convection electric field tends to accelerate ions in the "north" pole which is defined as the pole for which the convection electric field points away from the planet. In addition to this it was found that the shock produced a very non-isotropic pressure tensor (Brecht and Ledvina, 2010). It has also been found that loss rates are sensitive to the neutral profiles used even if the EUV flux is held constant. It has been repeatedly found that the loss rates do vary with the EUV flux and this variation seems to be consistent with the data from spacecraft. One sees that the pickup rates do not change linearly with increased EUV frequency (Brecht and Ledvina, 2010).

Another feature found in the simulations and reported in Brecht and Ledvina (2010) is the restricted region of the energetic ionospheric ions, as they escape. The energetic particles come from the "north pole" which is defined as the direction of the solar wind convection electric field. The particles can reach energies of greater than $10 \mathrm{keV}$. The energetic particles coming from the "north pole" are very consistent with measurements reported by Préz-de-Tejada et al. (2009). The loss region in the pole is very narrow in the dimension perpendicular to the ambient magnetic field. Of interest is the lower energy $\sim 10 \mathrm{eV} \mathrm{O}^{+}$seen to be com- 
Table 2. Simulation parameters.

\begin{tabular}{|c|c|c|c|c|c|}
\hline & Hot $\mathrm{O}$ corona & IMF (nT) & $\mathrm{SW}$ density $\mathrm{cm}^{-3}$ & Solar wind vel. $(\mathrm{km} / \mathrm{s})$ & Crustal field \\
\hline Solar min. & No & 3 & 2.7 & 485 & No \\
\hline Solar min. & Yes & 3 & 2.7 & 485 & No \\
\hline Solar min. & Yes & 3 & 2.7 & 485 & Yes \\
\hline Solar max. & Yes & 3 & 2.7 & 485 & No \\
\hline
\end{tabular}

Table 3. Loss rates in particles/s.

\begin{tabular}{cccc}
\hline & Solar min. with corona & Solar max. with corona & Solar min. with corona and crustal fields \\
\hline $\mathrm{O}^{+}$ & $4 \times 10^{24}$ & $9.3 \times 10^{24}$ & $2.5 \times 10^{23}$ \\
$\mathrm{O}_{2}{ }^{+}$ & $1 . \times 10^{26}$ & $6 . \times 10^{25}$ & $3 . \times 10^{24}$ \\
\hline
\end{tabular}

ing from the "southern" hemisphere. In fact more particles are being lost from the "southern" hemisphere than the "northern" hemisphere. This is unexpected as the convection electric field is nominally pointed into the planet on the "southern" hemisphere. However, in the "southern" hemisphere one finds a large region were there is at least some component of the electric field parallel to the local magnetic field which is essentially aligned along the flow axis in the tail region. The existence of the parallel fields explains how the $\mathrm{O}^{+}$is escaping in the "southern" hemisphere. It also explains some of the observations. The presence of the parallel electric fields was reported in Brecht and Ledvina (2010).

The "ISSI Challenge" called for three specific simulations to be performed. Neutral profiles were provided for both solar maximum and solar minimum. The IMF was 3 nT with a $56^{\circ}$ degree Parker spiral. The solar wind density was 2.7 protons $/ \mathrm{cm}^{3}$ with a velocity of $485 \mathrm{~km} / \mathrm{s}$. The Cartesian cell resolution was $150 \mathrm{~km}$ in each direction, so as to allow comparisons with other hybrid simulations. The chemistry/collision grid had a resolution of $10 \mathrm{~km}$ radially, and $1.9^{\circ}$ in latitude and longitude.

The total ion loss rate is a marker for what is going on within Mar's ionosphere. The loss rate has been examined for the ISSI solar minimum test cases; the solar minimum case without a hot oxygen corona and the solar minimum case where there is a hot oxygen corona. The ISSI solar maximum test case with the hot oxygen corona is also reported here. An additional simulation was performed for the solar minimum case with the Martian crustal magnetic fields included. The focus of this paper is the change in ionospheric loss rate as a function of these four simulations, Table 2.

The results for the solar minimum and solar minimum with hot oxygen corona were essentially the same. Although, it was shown in Brecht and Ledvina (2010) that the corona made a modification in the shock location due to the slight change in the solar wind Alfvén speed, there were found no significant difference in the global loss rate. The rates found for these cases are summarized in Table 3 . The solar minimum case calculated a loss rate of $4 \times 10^{24}$ particles/s for the $\mathrm{O}^{+}$and $1 \times 10^{26}$ particles/s for the $\mathrm{O}_{2}{ }^{+}$. Interestingly, the $\mathrm{O}_{2}{ }^{+}$loss rate is consistent with the maximum loss rates predicted by Fox (2009). These numbers represent a reduction of the previous $\mathrm{O}^{+}$loss rate from our Carte- sian simulations reported in Brecht and Ledvina (2010), $8 \times 10^{24}$ particles/s. and large increase in the $\mathrm{O}_{2}{ }^{+}$loss rate with this species now the largest of the ion loss species. This result was a complete surprise. It had been expected that the increased resolution of the chemistry would change the answers previously reported, but it was not expected that the numbers would reach this level. It had been noted by Ma $e t$ al. (2004) that the ratio of loss species switched when they went to higher resolution. The present results seem consistent with their findings.

It should be noted that these results are not consistent with the estimates from the data. Nor are they consistent with many of the other simulation groups. Interestingly, the loss rates for the solar maximum case with the hot oxygen corona were found to be $9.3 \times 10^{24}$ particles/s for the $\mathrm{O}^{+}$ and $6 . \times 10^{25}$ particles/s for the $\mathrm{O}_{2}{ }^{+}$. The $\mathrm{O}^{+}$loss rate is somewhat low as compared to that reported by Lundin et al. $(1989,1990)$ but the $\mathrm{O}_{2}{ }^{+}$loss rate seems consistent. The solar maximum rates are lower than those found for the solar minimum case and a bit lower than estimates from the data, yet the solar minimum is much higher than the estimates.

Finally, it was thought that perhaps the presence of the Martian crustal magnetic fields might help explain the solar minimum inconsistency with data. So the solar minimum simulation with the hot oxygen corona simulation was run with crustal magnetic fields included in the simulation. In this case, the field model used was by Purucker et al. (2000). The orientation of the crustal magnetic fields is shown in Fig. 5. We have plotted the crustal field at an altitude of $200 \mathrm{~km}$ with the $(0,0)$ coordinates at the subsolar point. The magnitude of $\mathbf{B}$ is plotted at the resolution of the fine grid $\left(1.9^{\circ}\right.$ or $112 \mathrm{~km}$ resolution in the angular dimensions). The plot is smeared out because we are filling each square with the interpolated field. Examination of figures 2 and 3 in Acuña et al. (1999) reveals that the resolution is very consistent with the data from which Purucker and others (cf. Cain et al., 2003) have created the crustal magnetic field models. The fields applied to the particles via the Lorentz force are interpolated field from the Cartesian grid $(150 \mathrm{~km})$. The features that the particles feel reflects more structure than is shown in Fig. 5. However, the general level of accuracy is reflected in the plot and this accuracy is consistent with the data as presented by Acuña et al. (1999).

The results of the simulation with the crustal magnetic 


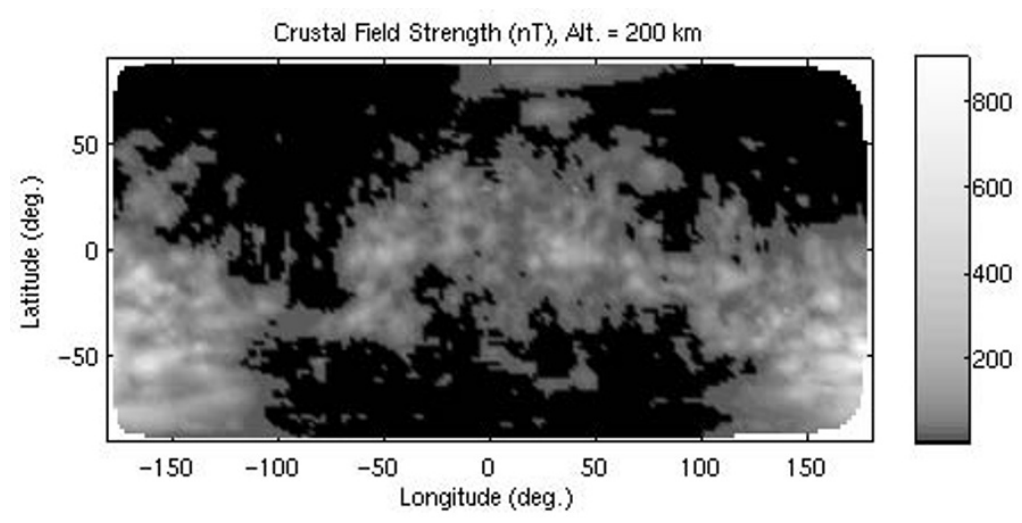

Fig. 5. Orientation of the Martian crustal magnetic fields. The magnitude of $\mathbf{B}$ is plotted at $200 \mathrm{~km}$ altitude in order to be compared to data from Acuña et al. (1999) (figures 2 and 3). The subsolar point is located at $(0,0)$ on this plot.

field are as follows: $2.5 \times 10^{23}$ particles/s for the $\mathrm{O}^{+}$and $3 . \times$ $10^{24}$ particles/s for the $\mathrm{O}_{2}{ }^{+}$. These results are consistent with the most recent estimates from the MEX spacecraft: $10^{23} \mathrm{O}^{+}$particles/s (Barabash et al., 2007) to $>10^{24} \mathrm{O}^{+}$ particles/s (Lundin et al., 2008). The predicted loss rates have changed by roughly 20 for $\mathrm{O}^{+}$and 30 for $\mathrm{O}_{2}{ }^{+}$from the previously estimated loss rates. The $\mathrm{O}_{2}{ }^{+}$loss rate is roughly 10 times higher than the $\mathrm{O}^{+}$loss rate, consistent with Fox (2009).

The results can be summarized as follows: the higher resolution chemistry simulations produce very different results than previously reported. The solar minimum results do not change with the addition of the hot oxygen corona. The solar minimum results are much higher than estimates from the data. Further, moving to the solar maximum situation the loss rates dropped for the $\mathrm{O}_{2}{ }^{+}$, but increased by a factor of two for the $\mathrm{O}^{+}$. Finally, inclusion of the crustal magnetic fields reduced the solar minimum loss rates to a value consistent with estimates from the data. The crustal magnetic field affects are always present in the Mars mission data unlike many of the simulations reported to date. The noncrustal fields simulations are more like Venus albeit with a smaller planet, smaller ionosphere, and weaker EUV flux. In the next section, the results will be discussed in light of further analysis of the simulations.

\section{Discussion}

The results presented seem to be contradictory. The solar minimum results providing much higher loss rates of molecular oxygen ions than atomic oxygen ions. The solar minimum molecular oxygen ion loss rates are higher than for solar maximum, while the atomic oxygen ion loss rate is lower for solar minimum than solar maximum as expected. Finally, the crustal magnetic fields are found to make a very large change in both species loss rates for the solar minimum case. In the next paragraphs further analysis will be presented to explain what at first seems to be counterintuitive results that are to some degree inconsistent with the data.

One place to begin is to examine the ionosphere. For the purposes of this discussion the altitude of choice is $250 \mathrm{~km}$ which is slightly above the exobase of the nominal ionosphere. Figure $6(\mathrm{a}, \mathrm{b})$ show the density of the $\mathrm{O}^{+}$and the
$\mathrm{O}_{2}{ }^{+}$for the no crustal field solar minimum case. The $\mathrm{O}^{+}$ seems to be greatly reduced in the subsolar region where $(0,0)$ is the subsolar point in latitude and longitude. The $\mathrm{O}_{2}{ }^{+}$is almost completely removed. In short, the electric fields are penetrating very deeply into the ionosphere and reaching altitudes where the $\mathrm{O}_{2}^{+}$density is very high. Examination of Fig. 7(a,b) shows the impact of the crustal magnetic fields. Note the high levels of the $\mathrm{O}^{+}$in the subsolar region dropping off to the night side. This is much closer to the initial ionospheric load and reflects the expected day-night drop off in density, see Fig. 8(a, b). The $\mathrm{O}_{2}{ }^{+}$, Fig. 7(b), shows a more uniform density as if it is being moved around but being contained in the ionosphere. There are significant holes in the density as one goes toward the terminator and the night side, but this may due to the statistical slice being taken: a $10 \mathrm{~km}$ slice at an instant in time. Enhancements and holes have been reported by a variety of researchers (cf., Nielsen et al., 2007; Gurnett et al., 2010). Both papers address the MARSIS data sets and found the enhancements were associated with crustal magnetic field cusps. At this point we cannot address this observation other than to point out the structure observed in a snapshot of the simulation. Yet, one can see from Fig. 6(a, b) and Fig. 7(a,b) that the structure in the ionosphere especially on the night side is only seen with the crustal fields in the model. This strongly suggests that the crustal field are the source of the structure at $250 \mathrm{~km}$ and the structure may be smaller size and more intense at lower altitudes. Since the MARSIS data requires $1.2 \mathrm{~s}$ to acquire, summing and averaging the simulation results over that length of time would be required for accurate comparisons.

Examining the radial velocity for each of these species provides more insight into what is occurring. Figure $9(a, b)$ show the radial velocity profile for both species. One sees that there are enhanced radial velocities in the polar regions especially the north pole and that the velocity is greatly enhanced on the night side of the planet. In Fig. 10(a, b) the radial velocity for both species is shown for the crustal magnetic field situation. One sees very low radial velocities with little spatial variation from day to night. This suggests that the pick up region is above $250 \mathrm{~km}$ when the crustal magnetic fields are included. This is consistent with the much lower loss rates and the very significant drop in the 

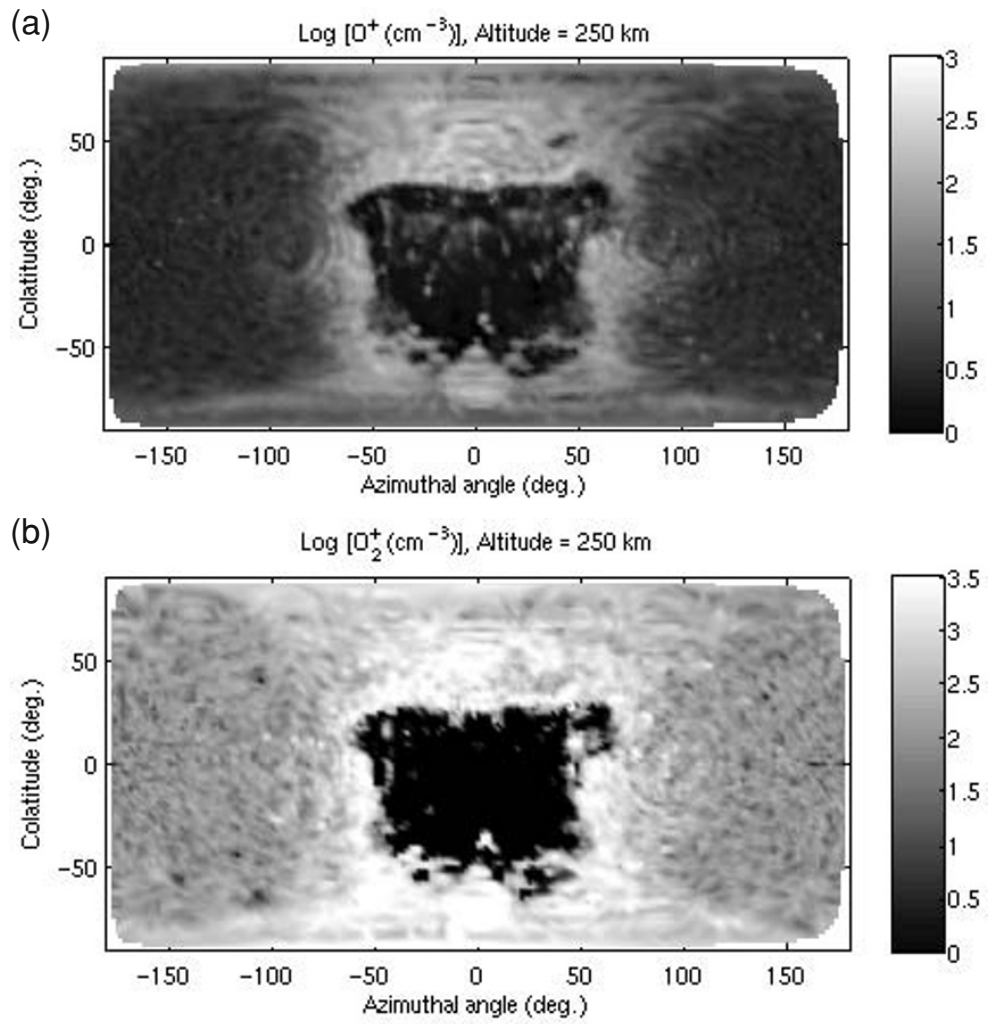

Fig. 6. The density of atomic (a) and molecular oxygen (b) ions with the no crustal magnetic fields present. The coordinate $(0,0)$ is the subsolar point on these plots.
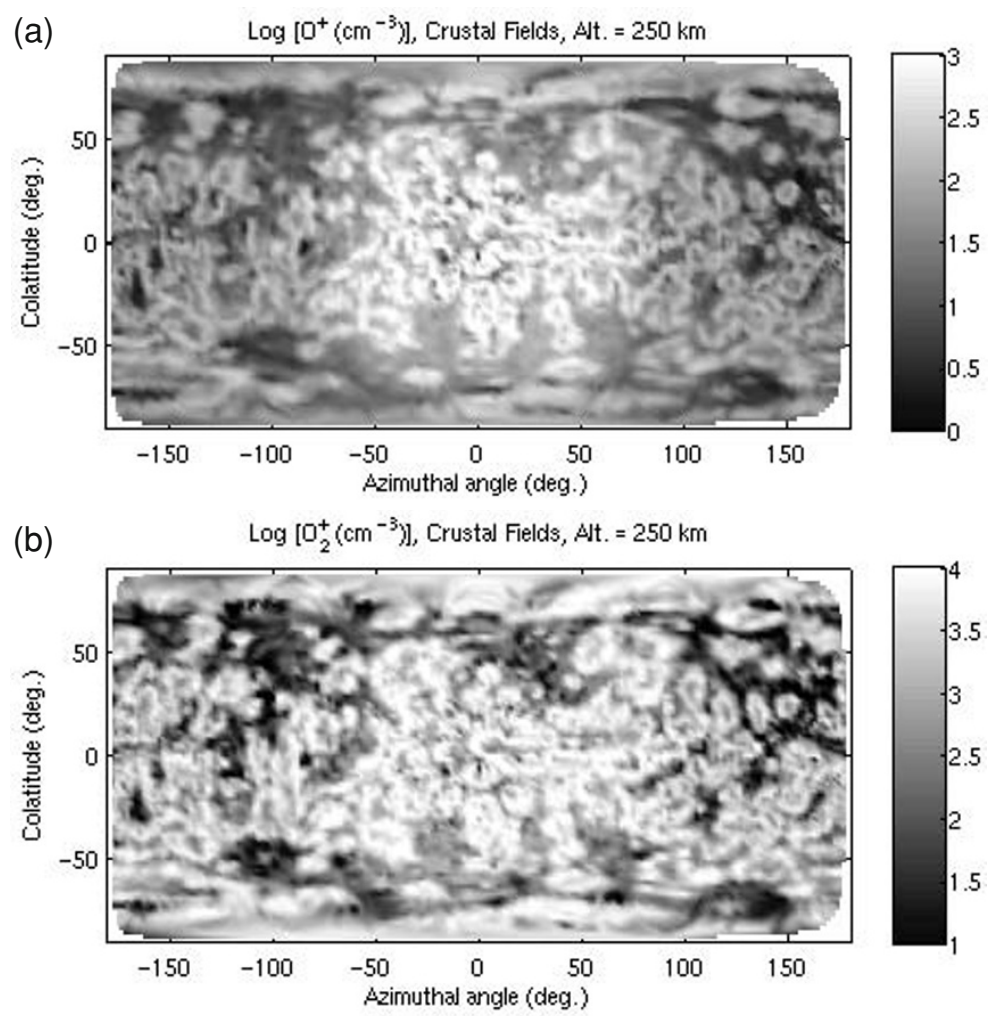

Fig. 7. The density of atomic (a) and molecular oxygen (b) ions with the crustal magnetic fields present. The coordinate $(0,0)$ is the subsolar point on these plots. 

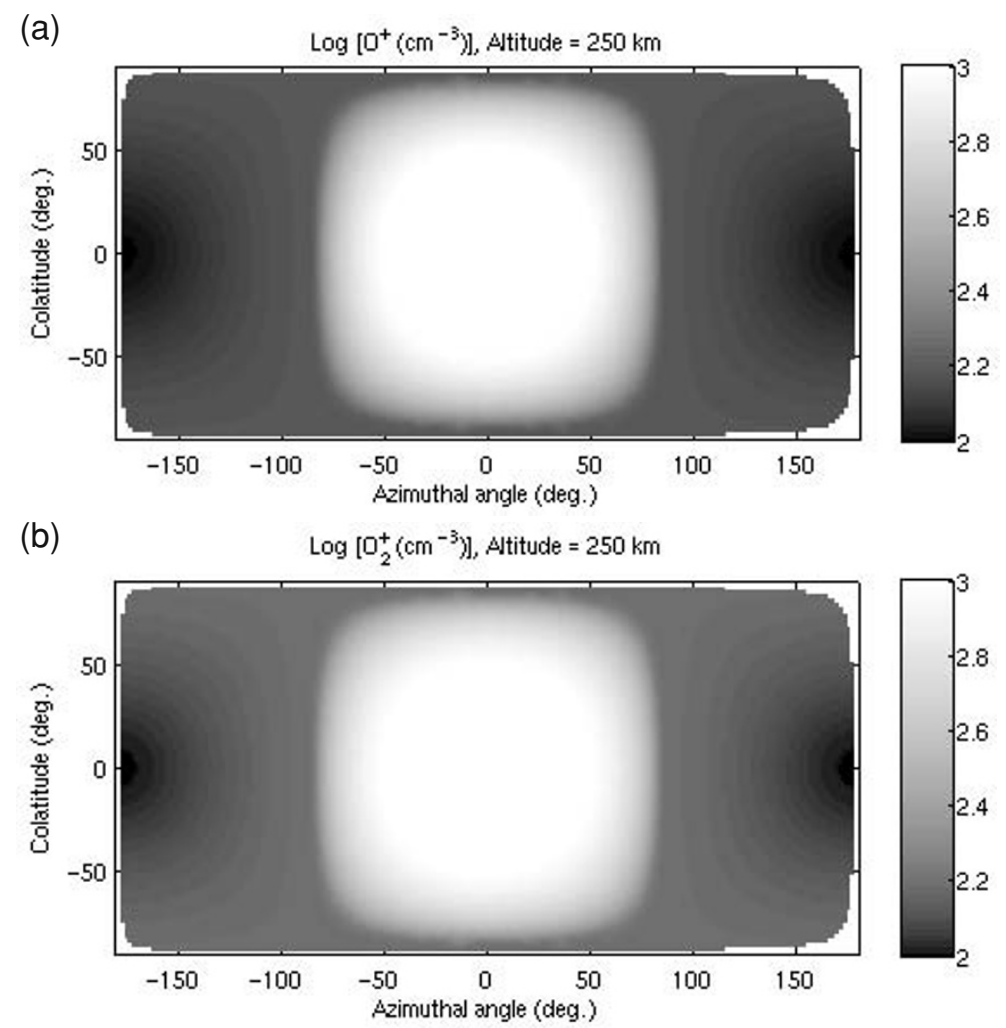

Fig. 8. Contours of the initial solar minimum load at $250 \mathrm{~km}$ altitude (a) is the oxygen ion load, (b) is the molecular oxygen ion load.
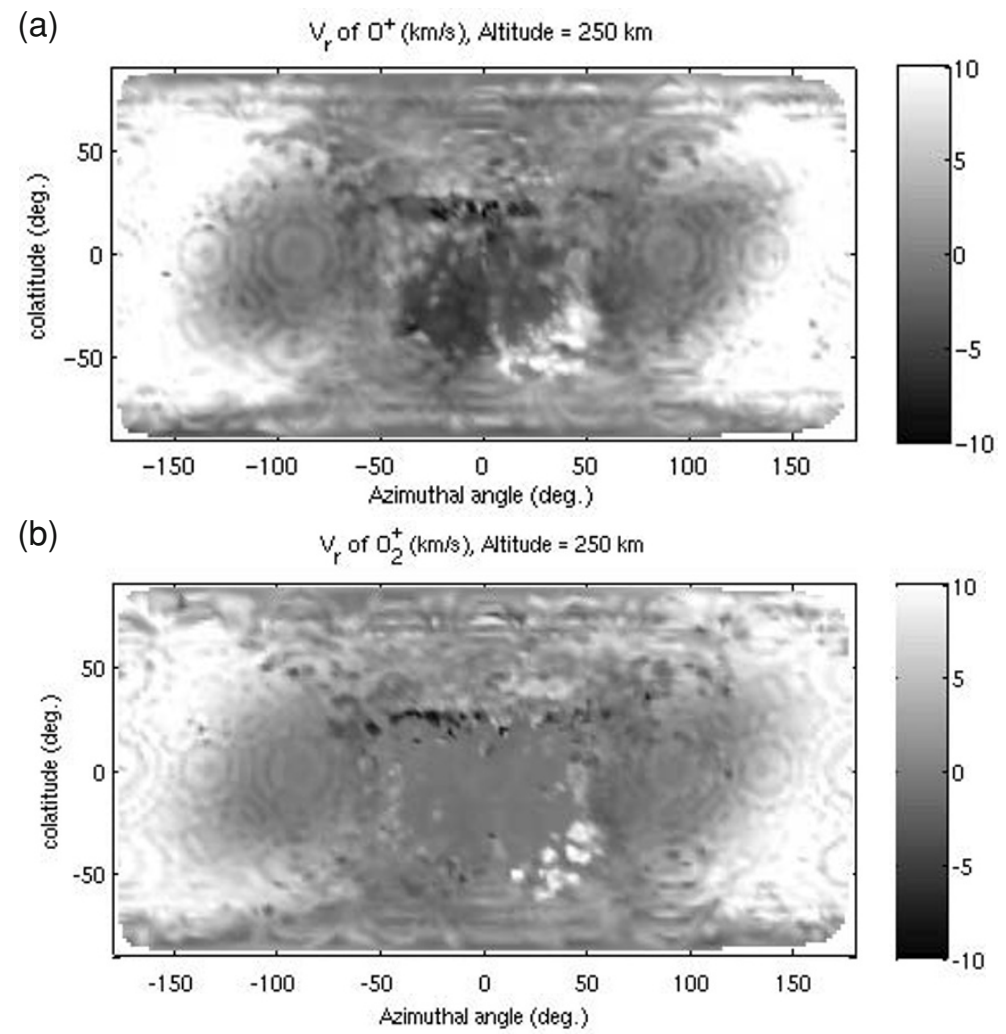

Fig. 9. The radial velocity of atomic (a) and molecular oxygen (b) ions with the no crustal magnetic fields present. The coordinate $(0,0)$ is the subsolar point on these plots. 

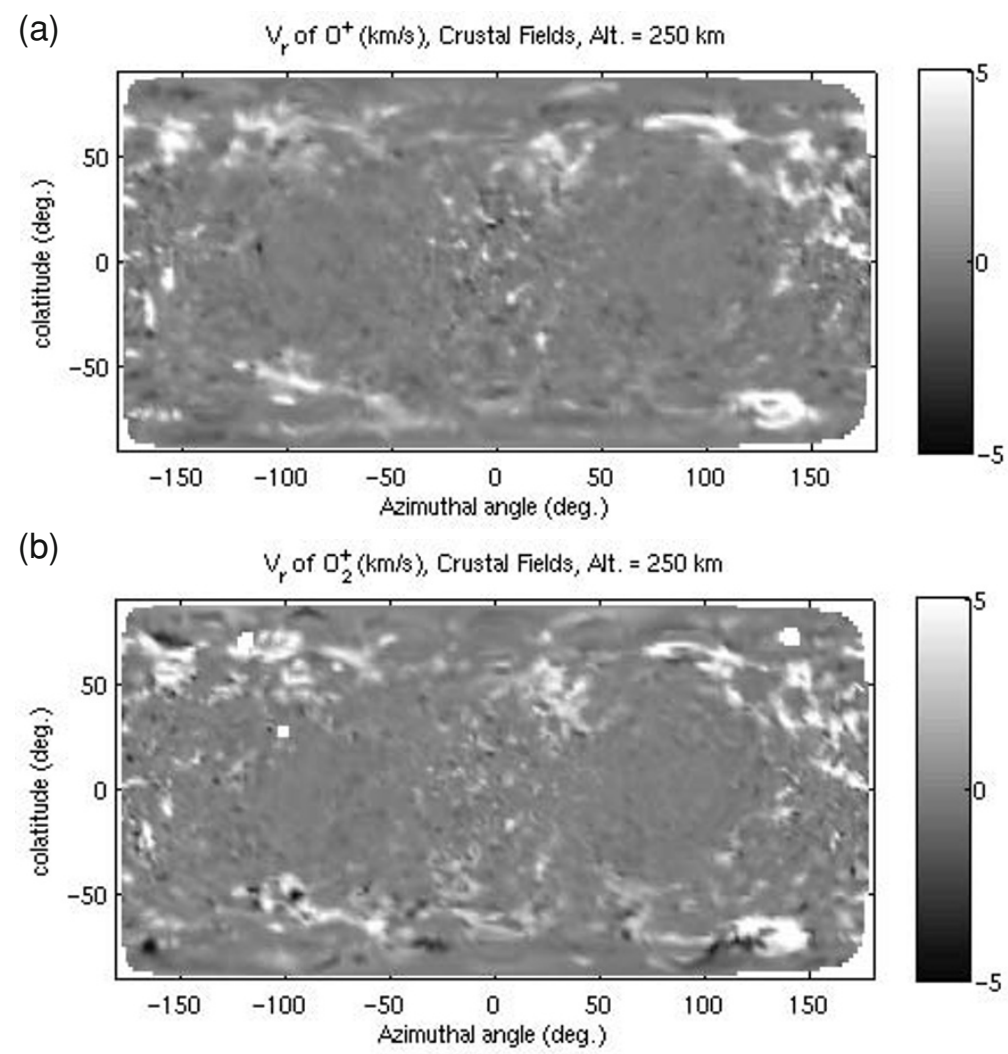

Fig. 10. The radial velocity of atomic (a) and molecular oxygen (b) ions with the crustal magnetic fields present. The coordinate (0, 0 ) is the subsolar point on these plots.

$\mathrm{O}_{2}^{+}$loss rate. In short the crustal fields have globally changed the electric field structure and greatly inhibited the flow of the ionosphere. Specifically, the night side escape at $250 \mathrm{~km}$ has been shut off by the presence of the crustal fields on the night side (see Fig. 5).

One can further examine the changes of the loss rates from solar minimum to solar maximum by looking at Figs. 2 and 3 and using the maximum net production rates for $\mathrm{O}^{+}$. For the solar minimum situation the maximum net ion production rate of $\mathrm{O}^{+}$is found to be 5.03 particles $/\left(\mathrm{cm}^{3} \mathrm{~s}\right)$ at $200 \mathrm{~km}$ altitude and 0.57 particles $/\left(\mathrm{cm}^{3} \mathrm{~s}\right)$ at $250 \mathrm{~km}$. One can obtain a flux from the net production rates by multiplying by a depth. In this paper the radial cell size $(10 \mathrm{~km})$ is used for the depth because it represents the minimum radial distance resolved with individual particles. Using a depth of $10^{6} \mathrm{~cm}$ and the net production rates described above, one obtains following flux estimates. At $200 \mathrm{~km}$ the net photochemical flux is $5.03 \times 10^{6}$ particles $/\left(\mathrm{cm}^{2} \mathrm{~s}\right)$ and at $250 \mathrm{~km}$ altitude the net flux is $5.7 \times 10^{5}$ particles $/\left(\mathrm{cm}^{2} \mathrm{~s}\right)$.

A loss rate of $10^{26}$ particles/s is equivalent to a loss flux of $1.2 \times 10^{8}$ particles $/\left(\mathrm{cm}^{2} \mathrm{~s}\right)$ over the whole planet. The $\mathrm{O}^{+}$loss rate of $4 \times 10^{24}$ particles/s is equivalent to a loss flux of $4.8 \times 10^{6}$ particles $/\left(\mathrm{cm}^{2} \mathrm{~s}\right)$. Comparing the net photochemical flux at $250 \mathrm{~km}$ to the global loss flux one sees that the photochemical flux $\left(5.7 \times 10^{5}\right.$ particles $\left./\left(\mathrm{cm}^{2} \mathrm{~s}\right)\right)$ is much less than the removed flux of $4.8 \times 10^{6}$ particles $/\left(\mathrm{cm}^{2} \mathrm{~s}\right)$. The $200 \mathrm{~km}$ net photochemical rate $\left(5.03 \times 10^{6}\right.$ particles $\left./\left(\mathrm{cm}^{2} \mathrm{~s}\right)\right)$ is large enough, suggesting that somewhere between $200 \mathrm{~km}$ and $250 \mathrm{~km}$ altitude the net photochemical rate can keep up with the advection and loss. This estimate is consistent with results shown in Fig. 6(a, b). Further, the loss region is local, as seen in Fig. 6, not global, therefore the actual local loss rates will exceed the averaged rates used in these estimates.

If one examines the solar maximum situation, Fig. 3, one obtains a different result. For the solar maximum the net production rates are 46.98 particles $/\left(\mathrm{cm}^{3} \mathrm{~s}\right)$ at $200 \mathrm{~km}$ altitude and 7.03 particles $/\left(\mathrm{cm}^{3} \mathrm{~s}\right)$ at $250 \mathrm{~km}$. Using $10 \mathrm{~km}$ as a depth at $250 \mathrm{~km}$, one obtains $7 \times 10^{6}$ particles $/\left(\mathrm{cm}^{2} \mathrm{~s}\right)$ for the net photochemical flux which is close to supporting a rate loss of approximately $9 \times 10^{6}$ particles $\mathrm{cm}^{-2} \mathrm{~s}^{-1}$ (equivalent to $8 \times 10^{24}$ particles/s, the measured loss rate for the solar maximum case). At $200 \mathrm{~km}$ the production rate is $4.7 \times 10^{7}$ particles $\mathrm{cm}^{-2} \mathrm{~s}^{-1}$ which is larger than the necessary $9 \times 10^{6}$ particles $\mathrm{cm}^{-2} \mathrm{~s}^{-1}$ needed for the advection loss rates. Thus, it is not surprising that one finds the $\mathrm{O}_{2}{ }^{+}$loss rates are lower for the solar maximum situation than for the solar minimum case. The $\mathrm{O}^{+}$chemistry is fast enough to overcome the advection at altitudes of $250 \mathrm{~km}$ or greater, thus shielding the $\mathrm{O}_{2}{ }^{+}$from the electric fields imposed by the solar wind.

Figures 11(a, b) show the photochemical equilibrium profiles for the solar minimum and solar maximum cases. In these figures one can see the slight shift in altitude $(230 \mathrm{~km}$ to $250 \mathrm{~km}$ ) where the $\mathrm{O}^{+}$dominates the $\mathrm{O}_{2}{ }^{+}$but the density of the $\mathrm{O}^{+}$is greatly enhance at higher altitudes in the solar maximum case providing more shielding of the solar wind electric fields. It can also be seen that with the crustal magnetic fields preventing the erosion at a high rate the pro- 


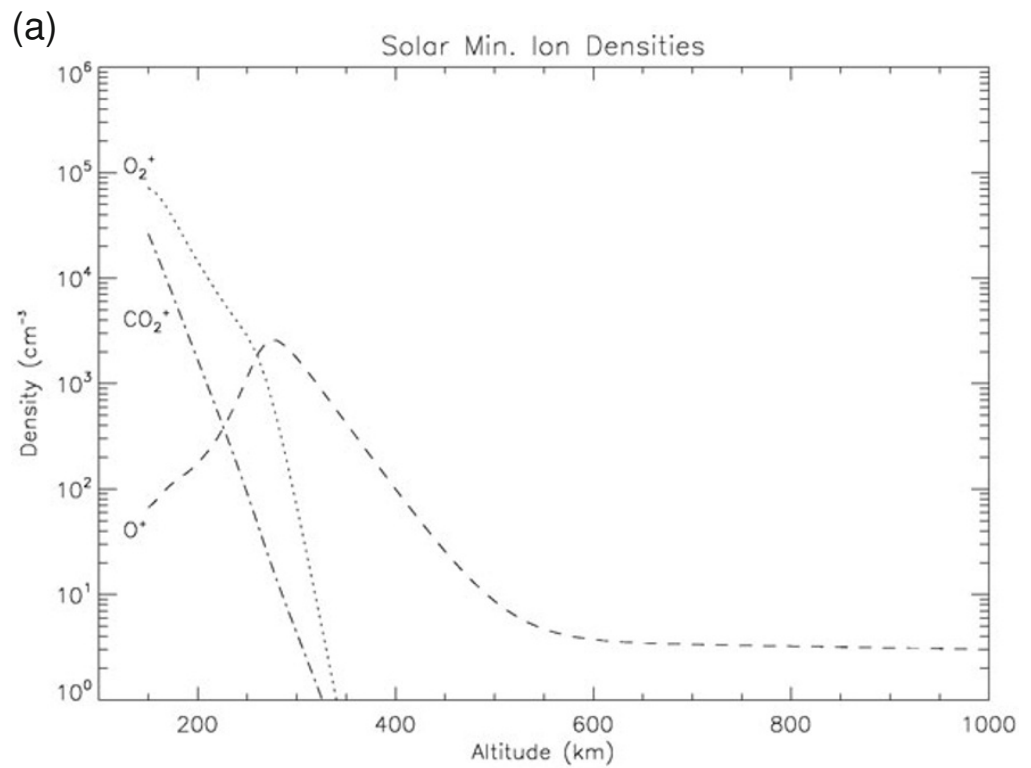

(b)

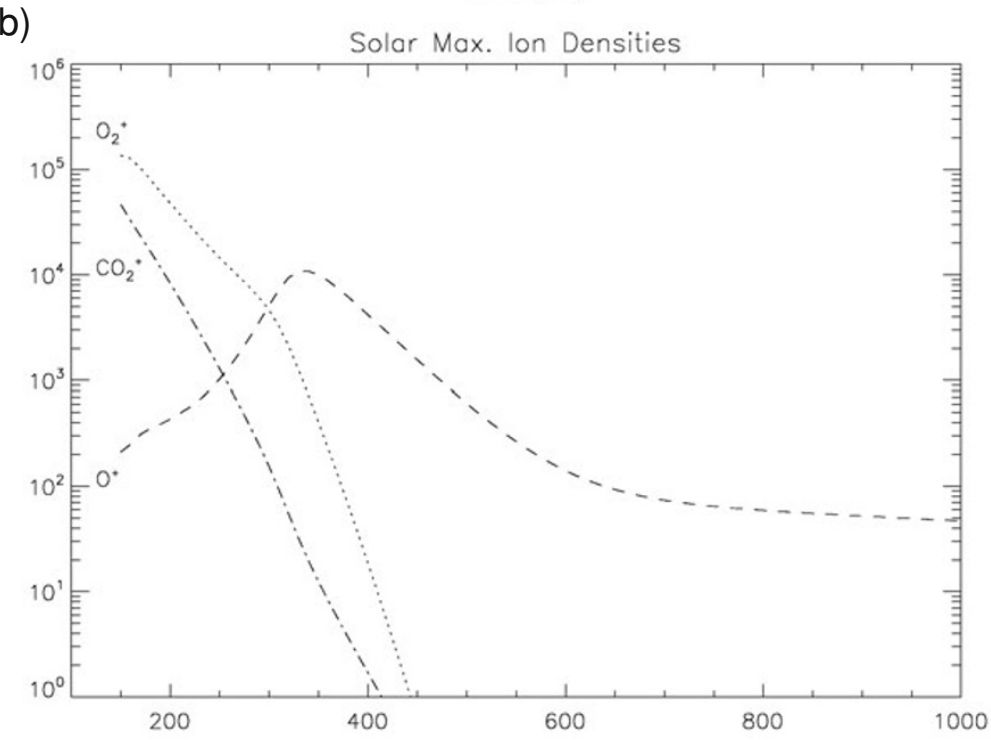

Fig. 11. Photochemical equilibrium for solar minimum and solar maximum (a) solar minimum case (b) the solar maximum case.

duction rate at solar minimum can keep up with or exceed the advection of the ionospheric plasma. Thus, there is a dynamic competition between the net photochemical production rates and the advection loss rates, and for the parameters specified for these simulations the balance point is near $250 \mathrm{~km}$. This discussion has not added the additional complexity of the production rates for $\mathrm{O}_{2}{ }^{+}$where one sees the peak rates occurring after about 100 seconds for the $200 \mathrm{~km}$ profiles. In both the solar minimum cases the production rate is not large enough/fast enough to build up as quickly as the advection, this is consistent with the hole seen in Fig. 6(b). At solar maximum the production rate is sufficient for all times at $200 \mathrm{~km}$ and $250 \mathrm{~km}$. It is clear though that at solar minimum the production rates of $\mathrm{O}_{2}{ }^{+}$ seem to be fast enough to make available a large amount of $\mathrm{O}_{2}{ }^{+}$for electric field pickup.

In summary, the results obtained in these simulations are consistent with the estimates of the chemical production rates. The issue is whether or not there is enough ionospheric plasma produced and maintained to shield the lower altitudes of the ionosphere where the $\mathrm{O}_{2}{ }^{+}$densities are very high and exceed the $\mathrm{O}^{+}$.

\section{Conclusions}

This paper has examined a variety of topics. These include: numerical issues, specifically the accuracy needed for high fidelity simulations of Mars' ionosphere; the affect of solar cycle variations on the global ion loss rates; the competition between photochemical rates and advection rates; and the impact of the crustal magnetic fields on the loss rates. All of the reported research has been focused on the solar minimum conditions used in the ISSI code comparisons (Brain et al., 2010).

It was found that increasing the chemistry resolution from $150 / 300 \mathrm{~km}$ resolution to performing the chemistry with $10 \mathrm{~km}$ radial resolution changed dominate loss species from $\mathrm{O}^{+}$to $\mathrm{O}_{2}{ }^{+}$during solar minimum. The $\mathrm{O}^{+}$loss rate dropped a factor of two from the published rates in Brecht and Ledvina (2010) while the $\mathrm{O}_{2}{ }^{+}$loss rates increased several orders of magnitude to $10^{26}$ particles/s. This increased 


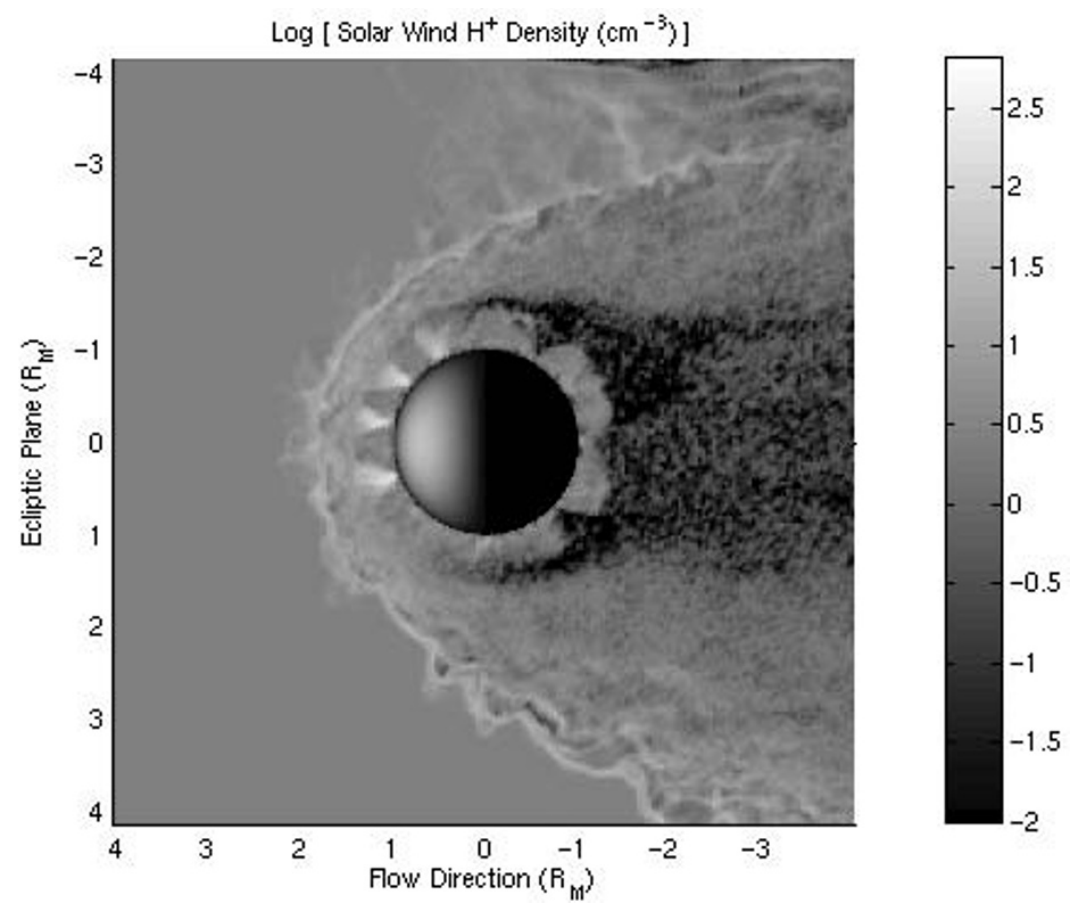

Fig. 12. An equatorial cut of the proton density from the solar minimum simulation with the crustal magnetic fields in the code. Note the focusing of the density into the magnetic cusps. It should also be noted that the protons loaded initially for the simulation are still trapped via collisions and the crustal field. This is clearly seen on the night side of the planet.

rate of loss for molecular oxygen ions is far above the best estimates from Phobos-2 or MEX.

It was also found that hot oxygen corona plays no significant role in the ion loss rates for the solar minimum case which is consistent with the low levels of ionization occurring in this situation. It is not clear if this statement is true for solar maximum situations. Research by Valeille et al. (2009a, b) suggests that the corona might change the simulations of the solar maximum situation. This will be examined in later research.

Comparison of a solar maximum situation with the solar minimum situation revealed a rather nonlinear behavior to the loss rates. The $\mathrm{O}^{+}$loss rate went up by a factor of 2 and the $\mathrm{O}_{2}{ }^{+}$loss rate dropped by a factor of 2 . This was explained by examining the changes in the net photochemical production rates as a function of altitude. The solar maximum case produces more $\mathrm{O}^{+}$at higher altitudes which in turn shields the $\mathrm{O}_{2}{ }^{+}$from the solar wind electric fields, thus strongly reducing the $\mathrm{O}_{2}{ }^{+}$pickup.

Finally, when the crustal magnetic fields were included in the solar minimum simulations there was a drop of a factor of roughly 20 in the $\mathrm{O}^{+}$loss rates and a drop of about 30 in the $\mathrm{O}_{2}^{+}$loss rates. This drop brought the estimated loss rates in line with the estimates from MEX during solar minimum. It was also found that inclusion of the crustal magnetic fields changed the location and shape of the ion loss channels for the $\mathrm{O}_{2}{ }^{+}$and $\mathrm{O}^{+}$as well as the total rates themselves.

The addition of the crustal magnetic fields changes the electromagnetic structure surrounding Mars. It is a global change which includes changing the shock shape, the shock location and the subsequent electric and magnetic field structure. Mars is a small planet not significantly larger than the solar wind proton kinetic gyroradius $(\sim 1300 \mathrm{~km}$ compared to $1 R_{\mathrm{M}}, 3395 \mathrm{~km}$ ). As such, local changes in the electromagnetic structures seem to change the whole structure. The interactions are very complicated due to feed back from the ionosphere into the global structure. So while one might speculate that the effects of the crustal magnetic fields would be local, the size of the planet and the extent of the crustal fields and how they disrupt the current flow around the planet do lead to global changes in the interaction.

Having said this, the results strongly suggests that other orientations of the crustal field with respect to the solar wind and the sun should lead to differing answers perhaps not as large as the change from no crustal field to having a crustal field. The affects of changing orientation remains as yet another issue to be examined in the future.

In summary, the set of simulations reported in this paper, clearly illustrate the competition between the photochemical processes and the advection of the ions away from the subsolar regions. Further, they illustrated the sensitivity of the loss rates to the altitude, magnitude and shape of the ionospheric profiles, which by inference illustrates the importance of the neutral profiles being used in these simulations. The results also suggest that a very counter intuitive behavior of Mars might be in play where the largest loss rates would occur for solar minimum rather than solar maximum, if the crustal fields and perhaps a global magnetic field did not exist for some period of time on Mars. It is worth noting that if the atmosphere is more extensive and of higher density, the photochemical rates go up rapidly and are further enhanced with increased EUV flux. This increase in the photochemical rate suggests that at earlier epochs Mars may not have lost as much atmosphere as one might have guessed due to shielding affects coupled with 
the change in balance between the photochemical process and advection as a function of altitude. The nonlinearity of results means projections of the sort just mentioned are very difficult to make without rather extensive simulations.

As usual, the results of this research leads to more questions than answers. These include everything from issue of the orientation of the crustal magnetic field to the solar wind, the role of ionospheric heating, and the role of the crustal magnetic field with regard to ionospheric behavior. From our standpoint what remains to be accomplished is to examine the loss rate as a function of the crustal magnetic field orientation. And to include more accurate 3-D models of the Martian atmosphere. It was determined in Brecht and Ledvina (2006) that changes in the day/night shape of the neutral profile made a significant difference in the loss rates. With these changes our future research will focus on more detailed aspects of the solar wind interaction with Mars. This includes the ionospheric flows and general behavior, comparisons between the solar minimum and solar maximum cases with the crustal magnetic fields, and finally local effects such as the role of plasma focusing by the crustal fields. And example of this is shown in Fig. 12. This figure shows significant focusing of the incoming protons hence energy deposition into the ionosphere by the protons. Considerably more research is required before one can claim to truly understand the interaction of the solar wind with Mars, because the simulations to date have demonstrated nonlinear and unexpected behavior of Mars as solar wind parameters are changed in conjunction with consistent neutral atmospheric profiles.

Acknowledgments. The authors of this paper would like to acknowledge the support from NASA grant NNH09CE73C, and NASA grant NNX08AK95G. In addition, the authors would like to acknowledge the ISSI support of an international team convened to compare global plasma models for Mars. The authors would like to acknowledge the computational support provided by the NASA Advanced Supercomputer, NAS, scientific computing facility at NASA Ames Research Center Moffett field CA. Finally, the authors would like to acknowledge and thank the referee's for their insightful comments and suggestions.

\section{References}

Acuña, M. et al., Magnetic field and plasma observations at Mars: initial results of the Mars Global Surveyor mission, Science, 279, 1676, 1998.

Acuña, M. H., J. E. P. Connerney, N. F. Ness, R. P. Lin, D. Mitchell, C. W. Carlson, J. McFadden, K. A. Anderson, H. Rème, C. Mazelle, D. Vignes, P. Wasilewski, and P. Cloutier, Global distribution of crustal magnetization discovered by the Mars Global Surveyor MAG/ER experiment, Science, 284(5415), 790-793, doi:10.1126/science.284.5415.790, 1999.

Barabash, S., A. Fedorov, R. Lundin, and J.-A. Sauvaud, Martian atmospheric erosion rates, Science, 315, 5811, 501-503, doi:10.1126/science.1134358, 2007.

Bößwetter, A., T. Bagdonat, U. Motschmann, and K. Sauer, Plasma boundaries at Mars: a 3-D simulation study, Ann. Geophys., 22, 4363, 2004.

Bougher, S. W., R. E. Dickinson, R. G. Roble, and E. C. Ridley, Mars thermospheric general circulation model-Calculations for the arrival of PHOBOS at Mars, Geophys. Res. Lett., 15, 1511-1514, 1988.

Brain, D., S. Barabash, A. Boesswetter, S. Bougher, S. Brecht, G. Chanteur, D. Hurley, E. Dubinin, X. Fang, M. Fraenz, J. Halekas, E. Harnett, M. Holmstrom, E. Kallio, H. Lammer, S. Ledvina, M. Liemohn, K. Liu, J. Luhmann, Y. Ma, R. Modolo, A. Nagy, U. Motschmann, H. Nilsson, H. Shinagawa, S. Simon, and N. Terada, A comparison of global models for the solar wind interaction with Mars, Icarus, 206(1), 139-151, doi:10.1016/j.icarus, 2010.
Brecht, S. H., Magnetic asymmetry of unmagnetized planets, Geophys. Res. Lett., 17, 1243, 1990.

Brecht, S. H., Solar wind proton deposition into the Martian Atmosphere, J. Geophys. Res., 102, 11,287, 1997a.

Brecht, S. H., Hybrid simulations of the magnetic topology of Mars, J. Geophys. Res., 102, 4743, 1997 b.

Brecht, S. H. and J. R. Ferrante, Global hybrid simulation of unmagnetized planets: Comparison of Venus and Mars, J. Geophys. Res., 96, 11209, 1991.

Brecht, S. H. and S. A. Ledvina, The solar wind interaction with the Martian Ionosphere/Atmosphere, Space Sci. Rev., 126, 15, 2006.

Brecht, S. H. and S. A. Ledvina, The loss of water from Mars: Numerical results and challenges, Icarus, 206(1), 164-173, doi:10.1016/j.Icarus.2009.04.028, 2010.

Brecht, S. H. and V. A. Thomas, Multidimensional simulations using hybrid particle codes, Comput. Phys. Commun., 48, 135, 1988.

Brecht, S. H., J. R. Ferrrante, and J. G. Luhmann, Three dimensional simulations of the solar wind interaction with Mars, J. Geophys. Res., 98, 1345, 1993.

Brecht, S. H., J. G. Luhmann, and D. J. Larson, Simulations of the Saturnian magnetospheric interaction with Titan, J. Geophys. Res., 105, 13,119, 2000.

Cain, J. C., B. B. Ferguson, and D. Mozzoni, An $\mathrm{n}=90$ internal potential function of the Martian crustal magnetic field, J. Geophys. Res. (Planets), 108, doi:10.1029/2000JE001487, 2003.

Chanteur, G. M., E. Dubinin, R. Modolo, and M. Fraenz, Capture of solar wind alpha-particles by the Martian atmosphere, Geophys. Res. Lett., 36, L23105, doi:10.1029/2009GL040235, 2009.

Chaufrey, J. Y., R. Modolo, F. Leblanc, G. Chanteur, R. E. Johnson, and J. G. Luhmann, Mars solar wind interaction: Formation of the Martian corona and atmospheric loss to space, J. Geophys. Res., 112(E9), E09009, 2007.

Cravens, T. E., J. U. Kozyra, A. F. Nagy, T. I. Gombosi, and M. Kurtz, Electron impact ionization in the vicinity of comets, J. Geophys. Res., 92(A7), 7341-7353, doi:10.1029/JA092iA07p07341, 1987.

Cravens, T. E., A. Hoppe, S. A. Ledvina, and S. McKenna-Lawlor, Pickup ions near Mars associated with escaping oxygen atoms, J. Geophys. Res., doi:10.1029/2001JA000125, 2002.

Di Achille, G. and B. M. Hynek, Ancient ocean on Mars supported by global distribution of deltas and valleys, Nature Geosci., doi:10.1038/ngeo891, 2010.

Fang, X., M. W. Liemohn, A. F. Nagy, J. G. Luhmann, and Y. Ma, Escape probability of Martian atmospheric ions: Controlling effects of the electromagnetic fields, J. Geophys. Res., 115, A04308, doi:10.1029/2009JA014929, 2010.

Fang, X., M. W. Liemohn, A. F. Nagy, J. G. Luhmann, and Y. Ma, On the effect of the martian crustal magnetic field on atmospheric erosion, Icarus, 206(1), 130-138, doi:10.1016/j.Icarus.2009.01.012, 2010.

Fox, J. L., Upper limits to the outflow of ions at Mars: Implications for atmospheric evolution, Geophys. Res. Lett., 24, 2901, 1997.

Fox, J. L., Morphology of the dayside ionosphere of Mars: Implications for ion outflows, J. Geophys. Res., 114(E12), E12005, 2009.

Gurnett, D. A., D. D. Morgan, F. Duru, F. Akalin, J. D. Winningham, R. A. Frahm, E. Dubinin, and S. Barabash, Large denisity fluctuations in the martian ionosphere as observed by the Mars Express radar sounder, Icarus, 206, 83-94, 2010.

Harned, D. S., Quasineutral hybrid simulations of macroscopic plasma phenomena, J. Comput. Phys., 47, 452, 1982.

Harnett, E. M. and R. M. Winglee, Three-dimensional multifluid simulations of ionospheric loss at Mars from nominal solar wind conditions to magnetic cloud events, J. Geophys. Res., 111, doi:10.1029/2006JA011724, 2006.

Kallio, E. and P. Janhunen, Ion escape from Mars in a quasi-neutral hybrid model, J. Geophys. Res., 107, doi:10.1029/2001JA000090, 2002.

Kim, J., A. F. Nagy, J. L. Fox, and T. E. Cravens, Solar cycle variability of hot oxygen atoms at Mars, J. Geophys. Res., 103, 29,339, 1998.

Lammer, H. and S. J. Bauer, Nonthermal atmospheric escape from Mars and Titan, J. Geophys. Res., 96, 1819, 1991.

Lammer, H., W. Stumptner, and S. J. Bauer, Loss of H and O from Mars: implications for the planetary water inventory, Geophys. Res. Lett., 23, 3353, 1996.

Lammer, H., H. I. M. Lichtennegger, C. Kolb, I. Ribas, E. F. Guinan, R. Abart, and S. J. Bauer, Loss of water from Mars: Implications for the oxidation of the soil, Icarus, 165, 9, doi:10.1016/S0019-1035(03)00170-2, 2003.

Ledvina, S. A., S. H. Brecht, and J. G. Luhmann, Ion distributions of 14 
AMU pickup ions associated with Titan's plasma interaction, Geophys. Res. Lett., 31, L17S10, 2004.

Ledvina, S. A., Y.-J. Ma, and E. Kallio, Modeling and simulating flowing plasmas and related phenomena, Space Sci. Rev., 139, 143-189, doi:10.1007/s11214-008-9384-6, 2008.

Liu, Y., A. F. Nagy, T. I. Gombosi, D. L. DeZeeuw, and K. G. Powell, The solar wind interaction with Mars: Results of the three-dimensional three species MHD studies, Adv. Space Res., 27, 1837, 2001.

Lundin, R., A. Zakharov, R. Pellinen, B. Hultquist, H. Borg, E. M. Dubinin, S. W. Barabash, N. Pissarenko, H. Koskinen, and I. Liede, First results of the ionospheric escape from Mars, Nature, 341, 609, 1989.

Lundin, R., A. Zakharov, R. Pellinen, S. W. Barabash, H. Borg, E. M. Dubinin, B. Hultquist, H. Koskinen, I. Liede, and N. Pissarenko, ASPERA/Phobos measurements of the ion outflow from the Martian ionosphere, Geophys. Res. Lett., 17, 873, 1990.

Lundin, R., E. M. Dubinin, H. Koskinen, O. Norberg, N. Pissarenko, and S. W. Barabash, On the momentum transfer of the solar wind to the Martian topside ionosphere, Geophys. Res. Lett., 18(6), 1059-1062, doi:10.1029/90GL02604, 1991.

Lundin, R., D. Winningham, S. Barabash, R. Frahm, H. Anderson, M. Holmström, A. Grigoriev, M. Yamauchi, H. Borg, J. R. Sharber, J.A. Sauvaud, A. Fedorov, E. Budnik, J.-J. Thocaven, K. Asamura, H. Hayakawa, A. J. Coates, D. R. Linder, D. O. Kataria, C. Curtis, K. C. Hsieh, B. R. Sandel, M. Grande, M. Carter, D. H. Reading, H. Koskinen, E. Kallio, P. Riihelä, W. Schmidt, T. Säles, J. Kozyra, N. Krupp, J. Woch, M. Fränz, J. Luhmann, S. McKenna-Lawler, R. Cerulli-Irelli, S. Orsini, M. Maggi, E. Roelof, D. Williams, S. Livi, P. Brandt, P. Wurz, and P. Bochsler, Ionospheric plasma acceleration at Mars: ASPERA-3 results, Icarus, 182, 308, 2006.

Lundin, R., S. Barabash, M. Holmstrm, H. Nilsson, M. Yamauchi, M. Fraenz, and E. M. Dubinin, A comet-like escape of ionospheric plasma from Mars, Geophys. Res. Lett., 35, L18203, doi:10. 1029/2008GL034811, 2008.

Lundin, R., S. Barabash, M. Holmstrm, H. Nilsson, M. Yamauchi, E. M. Dubinin, and M. Fraenz, Atmospheric origin of cold ion escape from Mars, Geophys. Res. Lett., 36, L17202, doi:10.1029/2009GL039341, 2009.

Ma, Y. A., A. F. Nagy, K. C. Hansen, and D. L. DeZeeuw, Threedimensional multispecies MHD studies of the solar wind interaction with Mars in the presence of crustal fields, J. Geophys. Res., 107, 1282, doi:10.1029/2002JA009293, 2002.

Ma, Y., A. F. Nagy, I. V. Sokolov, and K. C. Hansen, Three-dimensional, multispecies, high spatial resolution MHD studies of the solar wind interaction with Mars, J. Geophys. Res., 109, doi:10.1029/2003JA010367, 2004.
Ma, Y.-J. and A. F. Nagy, Ion escape fluxes from Mars, Geophys. Res. Lett., 34, L08201, doi:10.1029/2006GL029208, 2007.

Mazelle, C., D. Winterhalter, K. Sauer, J. G. Trotignon, M. H. Acuña, K. Baumgärtel, C. Bertucci, D. A. Brain, S. H. Brecht, M. Delva, E. Dubinin, M. Øierset, and J. Slavin, Bow shock and upstream phenomena at Mars, Space Sci. Rev., 111, 115, 2004.

Mitchner, M. and C. H. Kruger, Jr., Partially Ionized Gases, John Wiley \& Sons, NY, USA, 1973.

Modolo, R., G. M. Chanteur, E. Dubinin, and A. P. Matthews, Influence of the solar EUV flux on the Martian plasma environment, Ann. Geophys., 23, 433, 2005.

Nagy, A. F., D. Winterhalter, K. Sauer, T. E. Cravens, S. H. Brecht, C. Mazelle, D. Crider, E. Kallio, A. Zakharov, E. Dubinin, M. Verigin, G. Kotova, W. I. Axford, C. Bertucci, and J. G. Trotignon, The plasma environment of Mars, Space Sci. Rev., 111, 33, 2004.

Nielsen, E., M. Fraenz, H. Zou, J.-S. Wang, D. A. Gurnett, D. L. Kirchner, D. D. Morgan, R. Huff, A. Safaeinili, J. J. Plaut, G. Picardi, J. D. Winningham, R. A. Frahm, and R. Lundin, Local plasma processes and enhanced electron densitites in the lower ionosphere in magnetic cusp regions on Mars, Planet. Space Sci., 55, 2164-2172, 2007.

Nilsson, H., E. Carlsson, D. A. Brain, M. Yamauchi, M. Holmstrom, S. Barabash, R. Lundin, and Y. Futaana, Ion escape from Mars as a function of solar wind conditions: A statistical study, Icarus, 206(1), 40-49, doi:10.1016/j.icarus.2009.03.006, 2010.

Pérez-de-Tejada, H., R. Lundin, H. Durand-Manterola, and M. ReyesRuiz, Solar wind erosion of the polar regions of the Mars ionosphere, $J$. Geophys. Res., 114, A02106, doi:10.1029/2008JA013295, 2009.

Purucker, M., D. Ravat, H. Frey, C. Voorhies, T. Sabaka, and M. Acua, An altitude-normalized magnetic map of Mars and its interpretation, Geophys. Res. Lett., 27, 2449, 2000.

Valeille, A., M. R. Combi, S. W. Bougher, V. Tenishev, and A. F. Nagy, Three-dimensional study of Mars upper thermosphere/ionosphere and hot oxygen corona: 2. Solar cycle, seasonal variations, and evolution over history, J. Geophys. Res., 114, E11006, doi:10.1029/2009JE003389, 2009a.

Valeille, A., V. Tenishev, S. W. Bougher, M. R. Combi, and A. F. Nagy, Three-dimensional study of Mars upper thermosphere/ionosphere and hot oxygen corona: 1. General description and results at equinox for solar low conditions, J. Geophys. Res., 114, E11005, doi:10.1029/2009JE003388, 2009b.

Verigin, M. I. et al., Ions of planetary origin in the Martian magnetosphere (Phobos 2 / TAUS experiment), Planet. Space Sci.., 39, 134-137, 1991.

S. H. Brecht (e-mail: sbrecht@pacbell.net) and S. A. Ledvina 